\title{
HYDRO-METEOROLOGICAL FLOOD FORECASTING USING TANK MODEL WITH SATELLITE-BASED RAINFALL INPUT FOR KEMAMAN RIVER CATCHMENT
}

\author{
Ahmad Tarmizi Mat Taib, Wardah Tahir, Suzana Ramli, \\ Intan Shafeenar Ahmad Mohtar \\ Faculty of Civil Engineering, Universiti Teknologi Mara, \\ 40450 Shah Alam Selangor, Malaysia
}

\begin{abstract}
Flooding has always been one of the worst natural disasters in Kemaman Terengganu Malaysia. A reliable, timely and accurate flood forecasting system can improve flood preparedness. In this study, Tank Model was applied for flood forecasting at the upper catchment of the Kemaman River Basin. Hourly rainfall and water level data were used as input to the Tank Model. Autoregressive corrections were carried out to improve the simulated flood level at Rantau Panjang forecasting station. Five sets of data from selected storm events were used to calibrate the Tank Model and then the performance of the model was verified by using two (2) months of hourly rainfall data. A set of tank coefficients that suit the tank configuration selected for the Kemaman River Basin were determined by trial and error calibrations. Flood levels at Rantau Panjang, Kemaman were simulated with actual measured catchment rainfall and the Mean Absolute Error (MAE) was found to be $0.167 \mathrm{~m}$ and the model efficiency was $92 \%$. The Tank Model was found to be able to simulate and forecast the rising limb of the flood hydrograph as well as the runoff peak for the next $1 \mathrm{hr}$ to $4 \mathrm{hr}$. Once the tank model had been calibrated, satellite-based rainfall estimates were applied to evaluate the simulation and forecasting capability of the Tank Model. The forecast results show that direct application of the QPE from the satellite images needs further enhancement to improve the accuracy. The model developed is able to provide timely (lag time) and reliable warning at an average of 6 hours before the flood peak reaches Rantau Panjang Station, however the accuracy of water level forecast depends on the accuracy of the rainfall forecast
\end{abstract}

Keywords: Tank Model, flood forecast, Quantitative Precipitation Estimates (QPE), Satellite-Based Rainfall.

Cite this Article: Ahmad Tarmizi Mat Taib, Wardah Tahir, Suzana Ramli and Intan Shafeenar Ahmad Mohtar, Hydro-Meteorological Flood Forecasting Using Tank Model with Satellite-Based Rainfall Input for Kemaman River Catchment. International Journal of Civil Engineering and Technology, 11(1), 2020, 8-16. https://iaeme.com/Home/issue/IJCIET?Volume=11\&Issue $=1$ 


\section{INTRODUCTION}

Flooding has always been one of the worst natural disasters in Malaysia causing distress to more than 3.0 million affected people within the $29,000 \mathrm{~km}^{2}$ of flood prone areas [1]. A reliable, timely and accurate flood forecasting system can improve flood preparedness, thus reducing property damages, loss of lives and disruption to socio-economic development as well as assisting the authority in flood rescue operations. Some of the flood forecasting and warning systems operated for Malaysian rivers include the Stage-Correlation method (SCM), the Sacramento model, the Tank model, the Multivariate Non-linear Regression technique, the Linear Transfer Model [2], and Flood Watch [3]. Though many studies have been done on the application of flood forecasting models from sophisticated models such as Infoworks ${ }^{\mathrm{TM}}$ to simple stage-regression flood models, the Tank model has the advantage of being practical, less expensive and yet reasonably accurate. Since its initial conceptual development in the early 1960's, the Tank model $[4,5,6]$ has been modified based on some considerations including land use, urbanization factor and lag time. Development of PC based Tank Model real time flood forecasting system for Upper Klang Catchment had been studied by [7] using ground-based rainfall data.

Alternatives to gauged rainfall data as input to flood forecasting system are radar and satellite based rainfall. There are many cases that rain gauges were damaged due to ruinous flood events where alternative measurement of rainfall is direly needed. Advanced technique on improving the performance of flood forecasting system by coupling a rainfall-runoff model with satellite based quantitative precipitation forecast had been researched by [8] for upper Klang River Basin. In this study, the Tank model for Kemaman River, Terengganu, Malaysia was developed to model the river system and simulate flooding. As an enhanced approach, not only rainfall data from the ground rainfall station was used as input but also quantitative precipitation estimates (QPE) derived from the geostationary meteorological images were applied in the flood modelling and simulation.

\section{METHOD}

\subsection{Study Area and Hydrological Data}

The Kemaman River Basinis located at the southern part of the state and has a catchment area of 2,194 $\mathrm{km}^{2}$. The Kemaman River (Sungai Kemaman) originates from Cherul Forest Reserve near the boundary of Pahang and Terengganu. SungaiKemaman travels eastward through a total length of $100 \mathrm{~km}$ before reaching the sea. The main tributaries include $\mathrm{Sg}$ Cherul, $\mathrm{Sg}$ Tebak and Sg Jabor. The largest land cover is natural forest, the majority of which are located in Hulu Terengganu and Dungun. The economy is mainly dominated by petroleum and gas, followed by the tourism and fishing industries. These domestic and commercial activities are mainly situated along the coastal regions. Agriculture is also important, with fruit and vegetable farming leading the way. The Sg Kemaman catchment is a formation of 26 sub catchments based on their respective river tributaries as shown in Figure 1. The Sungai Kemaman catchment is influenced strongly by the Northeast monsoon which brings along heavy rainfall during the months of November to December. The duration of the rain event is long enough to cause flooding along some stretches of the river. The mean annual rainfall for the catchment is $3051 \mathrm{~mm}$. Due to the geographical location, the prevailing weather can be categorised into the following seasons, i.e. Northeast monsoon from October to January, the Southeast monsoon from June to September, and the inter-monsoon period from April to May. Flood occurs almost every year in Kemaman District when the water level in the river overtops a few meters above the danger level. 


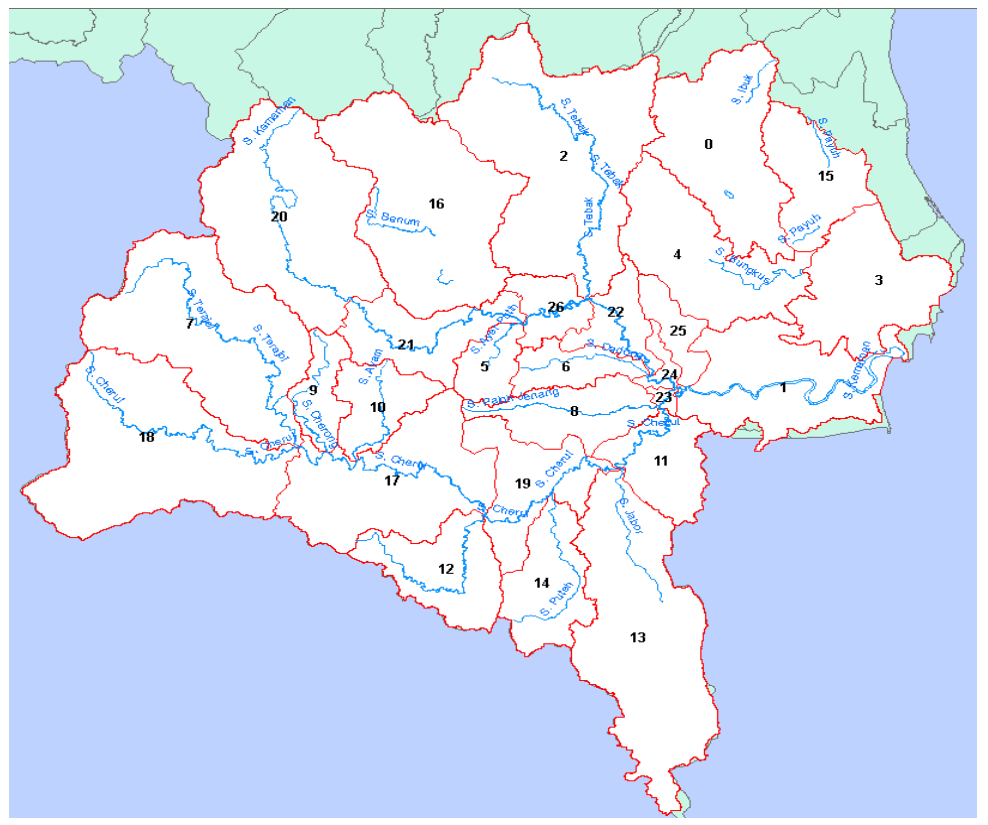

Figure 1. Kemaman River Catchment

Several sub-catchments at the upstream areas were selected to develop the hydrological model whose forecasted points are the available streamflow and water level at the station constructed by the DID. The available stream flow station is Sg Kemaman @ RantauPanjang (Station ID, 4232452). The streamflow data have been recorded since 1985. An hourly data from five (5) storm events were identified. The area of the selected catchment is about 636 $\mathrm{km}^{2}$ or $30 \%$ of the overall Kemaman River catchment area. For hydrological data, three (3) rainfall stations and one (1) water level discharges station were selected for this study.

\subsection{Methods}

Rainfall data, water level, stream flow and evaporation were collected and analysed using appropriate methods. The Double Mass Curve method was used for rainfall data consistency checking. All data collection was selected during storm events in the monsoon season. Five sets of flood data (15 Nov to 26 Nov 2009, 15 Nov to 30 Nov 2011, 28 Dec 2008 to 11 Jan 2009, 27 Nov to 11 Dec 2011 and 1 Jan 2009 to 8 Jan 2009) were used to calibrate the Tank model.

\subsection{Hydrological Tank Model Development}

The Tank Model is a simple lumped-parameter model that will transform rainfall into discharge for the forecasting of daily discharge or flood discharge. The model is composed of several tanks, usually four tanks for daily discharge. Each tank has an outlet on the side or /and at the bottom. Output through the side outlet will model the estimated discharge and output through the bottom outlet will simulate the infiltration as illustrated in Figure 2. 


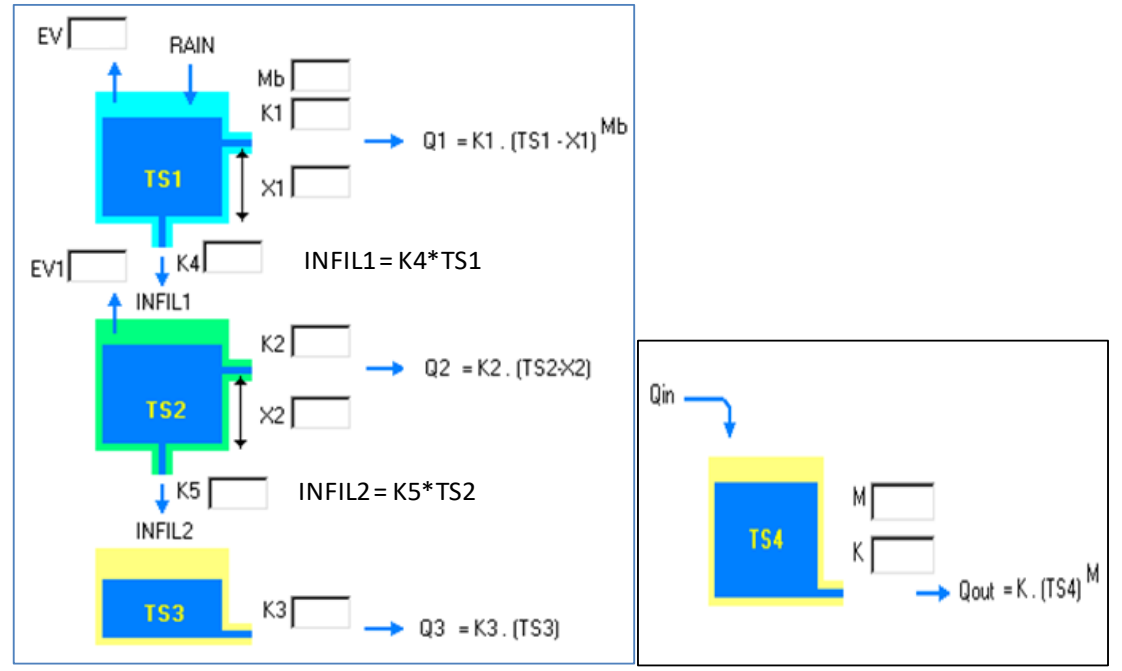

Figure 2 Schematic diagram of tank model

\subsection{Model Calibration and Validation}

Model calibration is a systematic process of adjusting model parameter values until results of the model match the observed data satisfactorily. Five historical storm events were used to calibrate the Tank Model (15 Nov to 26 Nov 2009, 15 to 30 Nov 2009, 28 Dec 2009 to 11 Jan 2009, 27 Nov to 11 Dec 2009, 1 Jan to 8 Jan 2009). All five storm events were calibrated simultaneously by referring to the same set of Tank model parameters $\left(\mathrm{K}_{1}, \mathrm{~K}_{2}, \mathrm{~K}_{3}, \mathrm{~K}_{4}, \mathrm{~K}_{5}\right.$, $\left.\mathrm{M}_{\mathrm{b}}, \mathrm{X}_{1}, \mathrm{X}_{2}, \mathrm{~K}, \& \mathrm{M}\right)$. The parameters were adjusted manually by trial and error by visually curve fitting of observed and simulated hydrograph. The model was checked numerically for its mean absolute error and model efficiency to finalise the best set of parameters that can provide the least error for all five historical storm events.

\subsection{Model Evaluation}

The accuracy of the model forecast was examined using the Nash-Sutcliffe Efficiency, (E) method:

$$
E=1-\frac{\sum_{t=1}^{n}\left(\operatorname{SIM}_{t}-O B S_{t}\right)^{2}}{\sum_{t=1}^{n}\left(O B S_{t}-O B S_{\text {mean }}\right)^{2}}
$$

\subsection{Autoregressive Analysis}

Auto Regressive analysis by Adaptive Adjustment (AR) was used with the aim to make an effective adjustment to improve the forecast capability of the Tank model. With adaptive adjustment (AR), the simulation error will be reduced. To obtain close fitting between simulated hydrograph with observed capture at water level station, the method used was:

$$
\text { FCSTQ }_{\mathrm{i}}=\mathrm{SIMQ}_{(\mathrm{i}-\mathrm{lhr})}+\left(\mathrm{RES}_{(\mathrm{i}-\mathrm{lhr})} * \mathrm{AR}_{\mathrm{j}}\right)
$$

Where

$$
\begin{array}{ll}
\text { FCSTQ }_{\mathrm{i}} & =\text { Forecast flood level for } \mathrm{i} \\
\operatorname{SIM}_{(\mathrm{i}-1 \mathrm{hr})} & =\text { Simulated flood level for }(\mathrm{i}-1 \mathrm{hr}) \\
\operatorname{RES}_{(\mathrm{i}-\mathrm{hr})} & =\text { Residue for (i-1hr) } \\
\mathrm{AR}_{\mathrm{j}} & =\text { Residue autoregressive coefficient for } \mathrm{j}
\end{array}
$$


Hydro-Meteorological Flood Forecasting Using Tank Model with Satellite-Based Rainfall Input for Kemaman River Catchment

$=1,2,3$ and $4(0100,0200,0300$ and 0400)

$=1,2,3$ and $4(1 \mathrm{hr}, 2 \mathrm{hr}, 3 \mathrm{hr}$ and $4 \mathrm{hr}$ forecast $)$

\subsection{Satellite Input Data Analysis}

Qualitative Precipitation Estimates (QPE) had been derived using the hourly rainfall intensity from MTSAT Weather Satellite such as shown in Figure 3.
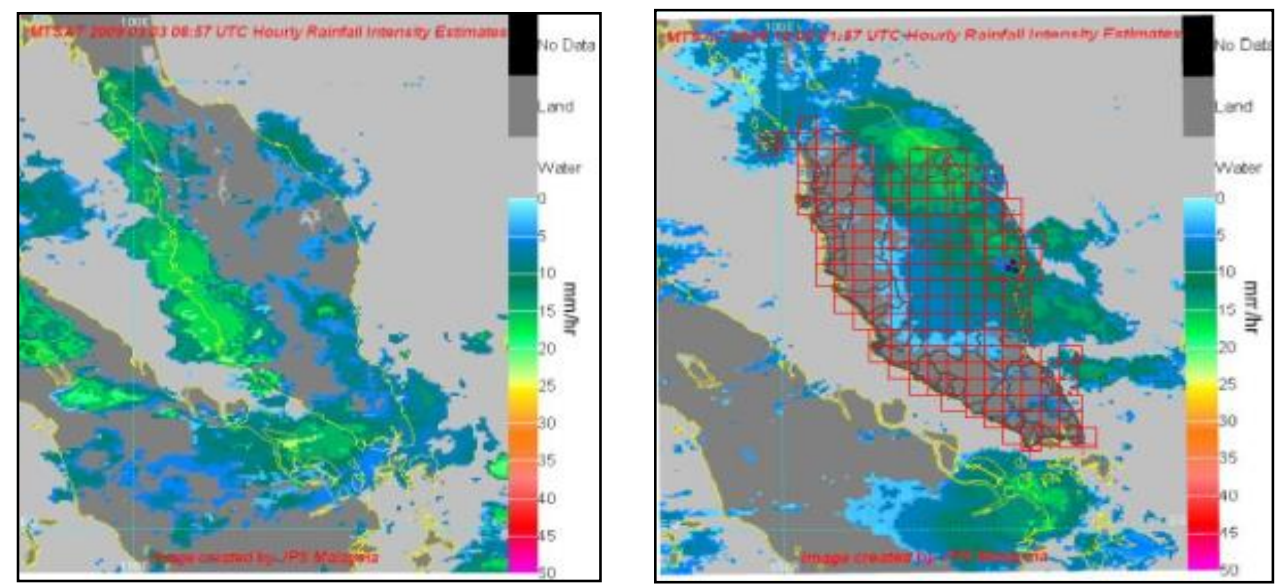

Figure 3 Hourly Rainfall Intensity Estimates Based on JPS MTSAT

Geographical Information System (GIS) software was used to overlay the satellite image onto a Peninsular Malaysia GIS map. Grids of $30 \mathrm{~km}$ x30 km were plotted onto the GIS map, and estimates of rainfall were made. An hourly data of satellite image was recorded by classified rainfall intensity colour scale as shown in Figure 3, for instance, dark green for 10 $\mathrm{mm} / \mathrm{hr}$, yellow for $25 \mathrm{~mm} / \mathrm{hr}$, red for $45 \mathrm{~mm} / \mathrm{h}$. The ground-based rainfall readings over the basin are compared with the readings obtained from the image from MTSAT. On real time basis, hydro-meteorological data was collected via a DID Info Banjir server and stored onto an MS Excel Tank Model file. The hydro-meteorological data was inserted into the flood forecasting model which comprised of real time ground based rainfall and observed water level as well as weather forecast time series based on statistical correlation from a MTSAT weather satellite.

\section{RESULTS AND DISCUSSION}

\subsection{Result of Model Calibration}

Five historical storm events were used to calibrate the Tank model (15 Nov to 26 Nov 2009, 15 to 30 Nov 2009, 28 Dec 2009 to 11 Jan 2010, 27 Nov to 11 Dec 2009, 1 Jan to 8 Jan 2009. After calibrating observed against simulated values at Rantau Panjang water level station, one set of parameters for the Tank model that provides the best fitting of hydrograph, highest model efficiency and mean absolute error for all five storm events was obtained. The observed and simulated water level hydrograph for the historical storm events are shown in Figure 4. From the hydrographs, it is observed that the simulated water level match closely with the recorded water levels. 


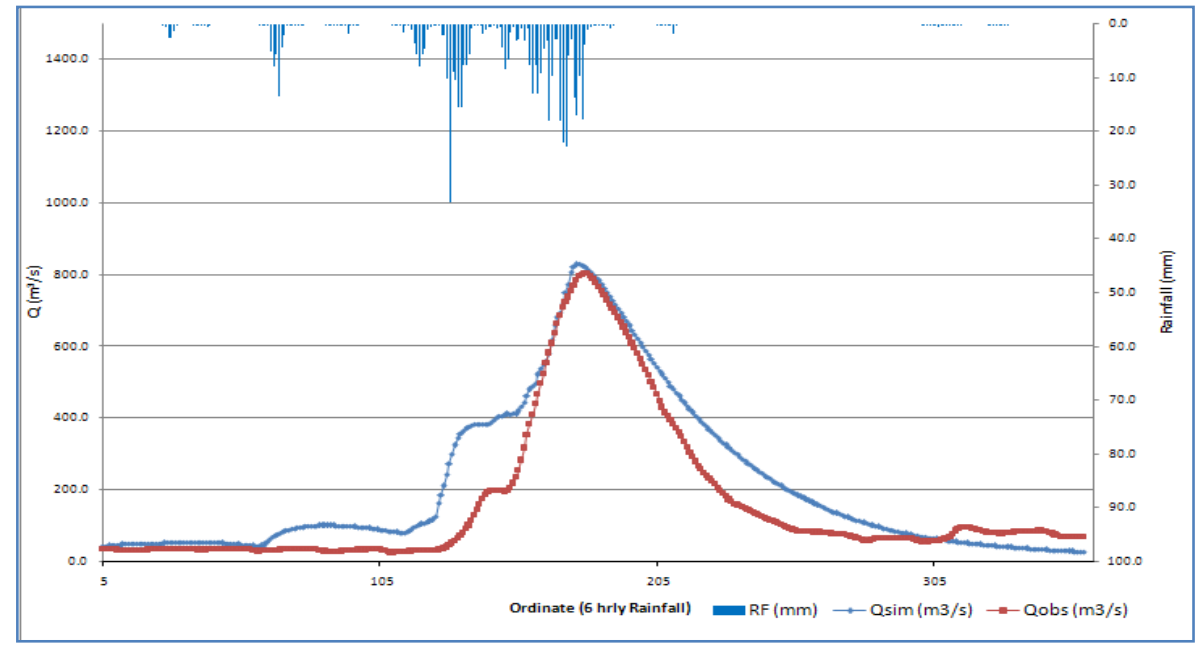

Figure 4 Observed and simulated discharge for storm event dated $28^{\text {th }}$ Dec 2009-1 $1^{\text {th }}$.Jan 2010.

The Mean Absolute Error and Efficiency are used as indicators during the trial and error process to obtain the best fit between observed and simulated water levels. From the calibration of five selected storm events, their errors are summarised in Table 1 (a). The average mean absolute error for all selected storm events is $0.167 \mathrm{~m}$ while the average model efficiency is $92.4 \%$. The same indicator was used to validate the Tank model and the parameter used in the calibration process was maintained in this process. The validation process using long term simulation ( 2 month) is used to check the reliability of the calibrated Tank model parameters as shown in Table 1 (b).

Table 1: Mean Absolute Error and Model Efficiency for (a) Short Term Simulation (b) Long Term Simulation

(a)

\begin{tabular}{lcc}
\hline \multicolumn{1}{c}{ Storm event } & $\begin{array}{c}\text { Mean } \\
\text { Absolute } \\
\text { Error (m) }\end{array}$ & $\begin{array}{c}\text { Model } \\
\text { efficiency } \\
(\boldsymbol{\%})\end{array}$ \\
\hline $\begin{array}{l}\text { 15 Nov - 30 Nov } \\
2011\end{array}$ & 0.29 & 92 \\
\hline $\begin{array}{l}\text { 27 Nov - 11 Dis } \\
\text { 2009 }\end{array}$ & 0.195 & 96 \\
\hline $\begin{array}{l}\text { 15 Nov - 26 Nov } \\
\text { 2009 }\end{array}$ & 0.21 & 94 \\
\hline 1 Jan-8 Jan 2009 & 0.09 & 96 \\
\hline $\begin{array}{l}\text { 28 Dec 2008-11 } \\
\text { Jan 2009 }\end{array}$ & 0.05 & 82 \\
\hline Average & 0.167 & 92 \\
\hline
\end{tabular}

(b)

\begin{tabular}{lcc}
\hline \multicolumn{1}{c}{ Storm Event } & $\begin{array}{c}\text { Mean } \\
\text { Absolute } \\
\text { Error }(\mathbf{m})\end{array}$ & $\begin{array}{c}\text { Model } \\
\text { Efficiency } \\
(\mathbf{\%})\end{array}$ \\
\hline $\begin{array}{l}\text { 1 Dec } 2008-31 \text { Jan } \\
2009\end{array}$ & 0.11 & 94 \\
\hline $\begin{array}{l}\text { 1 Nov } 2009-31 \mathrm{Dec} \\
\text { 2009 }\end{array}$ & 0.02 & 93 \\
$\begin{array}{l}\text { 1 Dec } 2010-31 \mathrm{Jan} \\
2010\end{array}$ & 0.11 & 79 \\
\hline $\begin{array}{l}\text { 1 Nov 2011-31 Dec } \\
\text { 2011 }\end{array}$ & 0.11 & 81 \\
\hline Average & 0.087 & 86.75 \\
\hline
\end{tabular}

\subsection{Autoregressive Analysis Results}

Auto regressive analysis by Adaptive Adjustment (AR) was used with the aim of making an effective adjustment to improve the forecast capability of the Tank Model. With adaptive adjustment (AR) for a lag time of 1 hour to 4 hours, the simulation errors were reduced. The autoregressive coefficient (AR) values are shown in Table 2.

Table 2 Auto Regressive Analysis Coefficient Result for Long Duration 
Hydro-Meteorological Flood Forecasting Using Tank Model with Satellite-Based Rainfall Input for Kemaman River Catchment

\begin{tabular}{ccccc}
\hline \hline Storm Event & AR Lag 1 & AR Lag 2 & AR Lag 3 & AR Lag 4 \\
\hline 1 Dec 2008 - 31 Jan 2009 & 0.9864 & 0.9543 & 0.9121 & 0.8648 \\
\hline 1 Nov 2009-31 Dec 2009 & 0.9949 & 0.9877 & 0.9622 & 0.8989 \\
\hline 1 Dec 2010 - 31 Jan 2010 & 0.9909 & 0.9665 & 0.9303 & 0.8861 \\
\hline 1 Nov 2011 - 31 Dec 2011 & 0.9968 & 0.9892 & 0.9798 & 0.966 \\
\hline Average & 0.9922 & 0.9744 & 0.9461 & 0.9039 \\
\hline \hline
\end{tabular}

The reliability checking process of the calibration and validation of the model after applying the average autoregressive coefficient is then used for one of the short duration storm events, i.e. from 15 Nov to 26 Nov 2009. From the result, the error improvement after adaptive adjustment for 1 hour, 2 hour, 3 hour and 4 hour on validation hydrograph by calculating the Mean Absolute Error (MAE and the Nash-Sutcliffe Efficiency (E) are shown in Table 3

Table 3 Error Improvement After Adaptive Adjustment

\begin{tabular}{|c|c|c|c|}
\hline \multirow{3}{*}{\multicolumn{2}{|c|}{ Forecast }} & \multicolumn{2}{|c|}{ Average Errors } \\
\hline & & MAE & Nash-Sutcliffe Efficiency \\
\hline & & (m) & $(\%)$ \\
\hline \multicolumn{2}{|r|}{ Simulation } & 0.21 & 94.96 \\
\hline \multirow{4}{*}{ 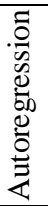 } & 1 hour & 0.001 & 99.91 \\
\hline & 2 hour & 0.21 & 94.48 \\
\hline & 3 hour & 0.20 & 93.04 \\
\hline & 4 hour & 0.19 & 91.64 \\
\hline
\end{tabular}

\subsection{Satellite Data Results}

Two storm events were used to simulate this Tank Model using satellite rainfall data which is from $21^{\text {st }}$ to $23^{\text {rd }}$ November 2009 and from $2^{\text {nd }}$ to $5^{\text {th }}$ December 2009. Figure 5 shows the patterns of rainfall time series from rainfall data recorded by the rain gauge (ground rainfall) and satellite-based rainfall estimate.

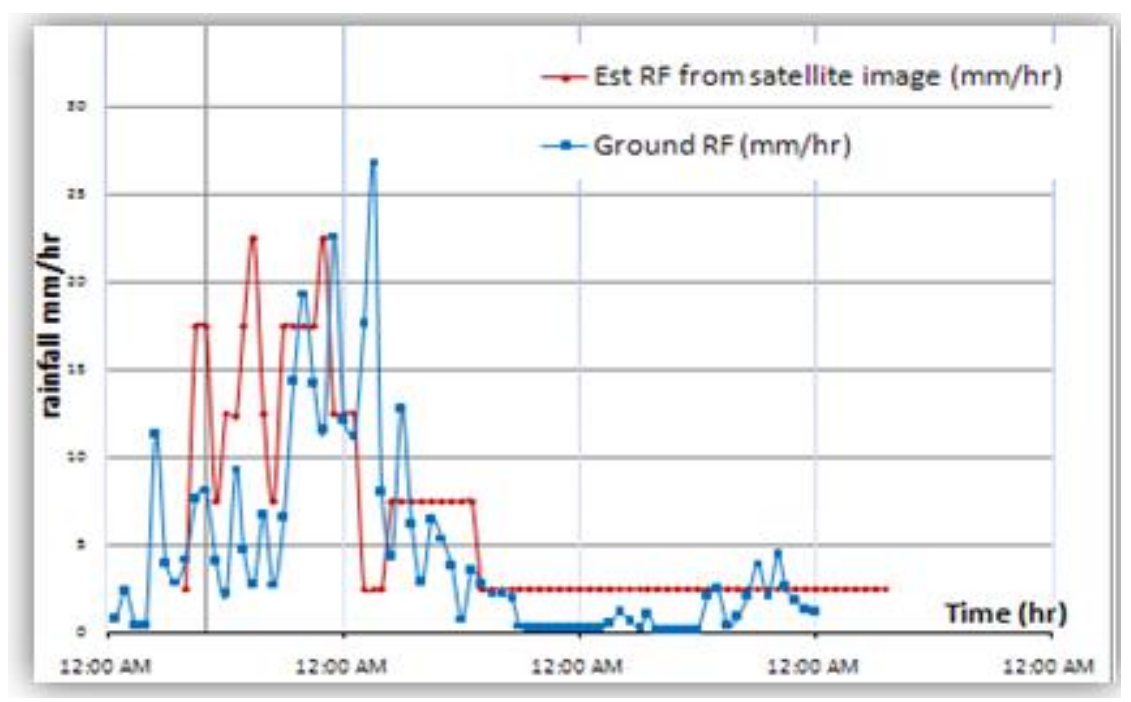

Figure 5 Comparison of Rainfall Time Series on $21^{\text {st }}$ to $23^{\text {rd }}$ November 2009 Storm Event

By using this satellite-based rainfall estimate, the values are keyed-in into the Tank Model and results are shown in Figure 6. From the figure, it can be concluded that the satellite rainfall produces almost similar results to ground rainfall during rising limb. Nevertheless, the 
peak storm event shows ground-based rainfall contributed a higher value (observed discharge) compared to simulated discharge.

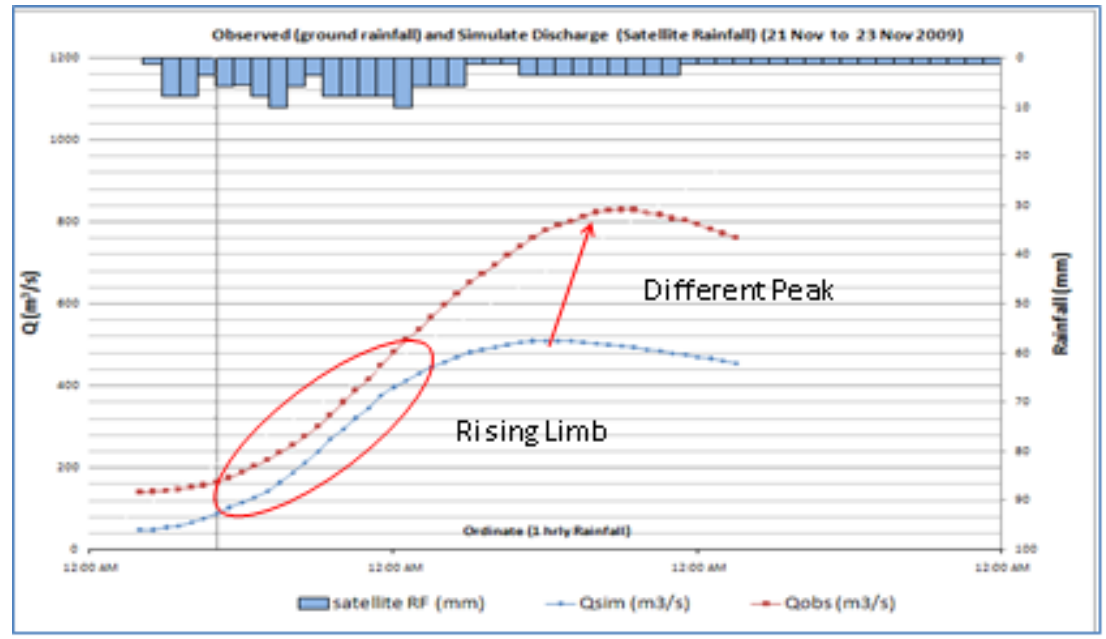

Figure 6 Comparison of Observed Discharge (using ground rainfall) and Simulated Discharge (using satellite rainfall) on $21^{\text {st }}$ to $23^{\text {rd }}$ November 2009 Storm Event.

The rating curve equation was used to convert from discharge into water level. Figure 7 shows the observed and forecasted water level during the 21st to 23rd November 2009 storm event

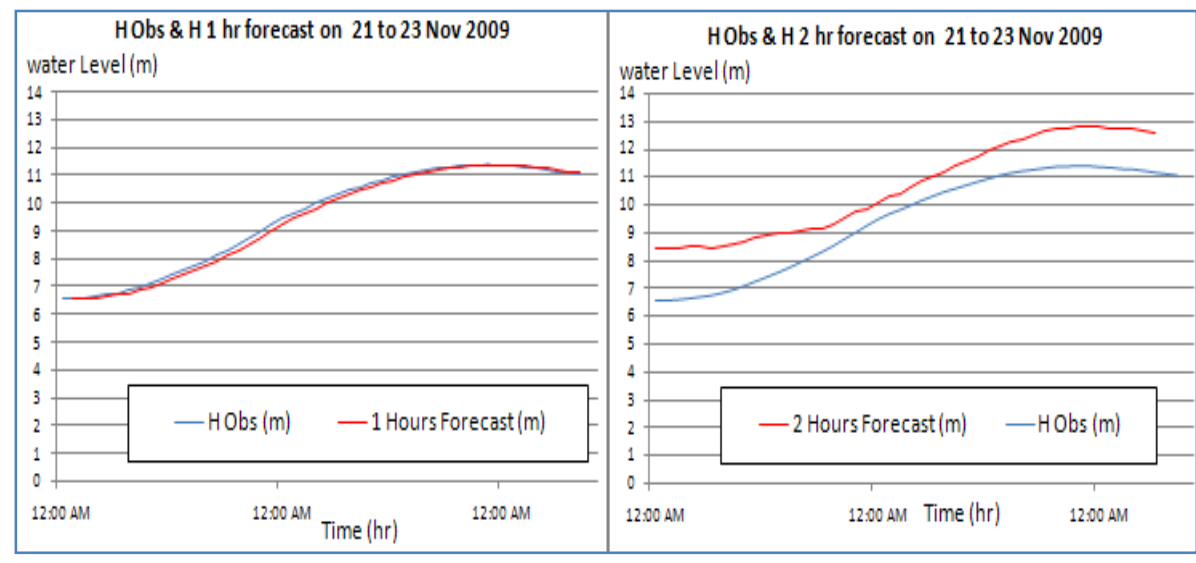

Figure 7 Observed and Simulated Water Level on $21^{\text {st }}$ to $23^{\text {rd }}$ November 2009 Storm Event

The average mean absolute error for the selected storm event is $1.81 \mathrm{~m}$ although the average model efficiency is $96.2 \%$. Figure 7 also shows that the model works better using the 1-hour forecast compared to the 2-hour forecast.

Based on the result, the satellite-based rainfall estimate can help to forecast the flood level using the Tank Model but the forecast results show that direct application of the QPE from the satellite images need further enhancement to improve the accuracy. This is because the satellite sensor captures the cloud top brightness temperature and only indirect correlation was made to produce the QPE. Nevertheless, satellite based rainfall information has very potential to produce reliable and wide-coverage rainfall estimates as alternative to gauged rainfall. 
Hydro-Meteorological Flood Forecasting Using Tank Model with Satellite-Based Rainfall Input for Kemaman River Catchment

\section{CONCLUSION}

The simulation results for long-term storm event duration shows that the model efficiency is more accurate compared to a short-duration storm event. The average mean absolute error for short term duration is higher (more than $0.167 \mathrm{~m}$ ). It occurs during the rising limb or time to peak, whereby the difference in water levels between observed and simulated levels is almost $0.5 \mathrm{~m}$ but at the peak discharge the difference in water level is almost negligible. Based on the simulation results, there are significant differences in the simulated discharge between ground-based and satellite-based rainfall. The rainfall pattern between these two is identical, but the peak value for ground-based rainfall is higher compared to satellite-based rainfall. The model developed is able to provide timely and reliable warning at an average of 6 hours before the flood peak reaches Rantau Panjang Station. It is also concluded that the difference between the simulated results of discharge hydrograph using satellite-based rainfall and the measured observed discharge is due to the difference in rain estimates, and the observation accuracy of satellite-based rainfall. The satellite-based rainfall estimate has many advantages compared to rainfall information observed by gauges on the ground, but it lacks in accuracy, thereby much improvement is needed before it can be applied directly for flood estimation.

\section{ACKNOWLEDGEMENTS}

The authors wish to thank the Department of Irrigation and Drainage (DID) Malaysia and Institute of Research, Development and Commercialization of Universiti Teknologi MARA for research grant 600-IRMI/PERDANA 5/3/MITRA (004/2018)-1).

\section{REFERENCES}

[1] Azmi, M. J. (1992), Application of a Flood Forecasting Model to The Kelantan River Basin in Malaysia. International Symposium on Torrential Rain and Flood, Kuala Lumpur.

[2] Chong, S.F. and Amin, M.Z.M (2001) Flood Forecasting Systems in Malaysia, National Conference on Hydraulics, Hydrology and Sustainable Water Resources Development, Bangi, Malaysia 24-26 September.

[3] Wong W.S (2006) Klang River Basin Flood Modeling and Forecasting System, River Protection and Watershed Modeling Seminar, Shah Alam, Malaysia.

[4] Suguwara, M. (1979), Automatic Calibration of Tank Model, Hydrological SciencesBulletin. 24 No 3.

[5] Suguwara, M and I. Watanabe (1983), Reference Manual of the Tank Model. National Research Center for Disaster Prevention, Japan.

[6] Sugawara.M, (1986): Reference Manual for The Tank Model. National Research Centre for Disaster Prevention, Tokyo.

[7] Cheok H.S, (2005): Development of PC Based Tank Model Real Time Flood Forecasting System. Faculty of Civil Engineering, UniversitiTeknologi Malaysia.

[8] Wardah, T., Abu Bakar, S.H., Bardossy, A., Maznorizan, M., 2008. Use of geostationary meteorological satellite images in convective rain estimation for flash-flood forecasting. Journal of Hydrology 356 (3-4), pp. 283-298. 